\title{
Early vs deferred highly active antiretroviral therapy in HIV infected infants: a European Collaborative Cohort Study
} Tessa Goetghebuer*1, Edwige Haelterman'1, Jerome Le Chenadec ${ }^{2}$, Catherine Dollfus ${ }^{3}$, Diana Gibb ${ }^{4}$, Katherine Boyd ${ }^{4}$, Ali Judd ${ }^{4}$, Luisa Galli5, Clara Gabiano $^{5}$, Jose Ramos ${ }^{6}$, Claire Thorne ${ }^{7}$, Magdalena Marczynska ${ }^{8}$, Olivia Keiser ${ }^{9}$, Luminita Ene ${ }^{10}$, Marc Hainaut ${ }^{1}$, Henriette Scherpbier ${ }^{11}$, Uwe Wintergerst ${ }^{12}$, Véronique Schmitz ${ }^{13}$, Gwenda Verweel ${ }^{14}$, Carlo Giaquinto ${ }^{15}$, Josiane Warszawski ${ }^{2}$ and Jack Levy ${ }^{1}$

\begin{abstract}
Address: ${ }^{1}$ Paediatric Department, CHU St Pierre, Brussels, Belgium, ${ }^{2}$ Institut National de la Santé et de la Recherche Médicale, Paris, France, ${ }^{3}$ APHP, Hôpital Trousseau, Service d'Hématologie et d'oncologie pédiatrique, Paris, F-75571 France, ${ }^{4}$ MRC Clinical Trials Unit, London, UK, ${ }^{5}$ Italian Register, Department of Paediatrics, University of Florence, Italy, ${ }^{6}$ Hospital 12 Octubre, Madrid, Spain, 7 ECS, institute of Child Health, London, UK, ${ }^{8}$ Infectious Disease Hospital, Medical University Warsaw, Poland, ' ${ }^{9}$ ata Center of the Swiss HIV Cohort Study, Lausanne, and Institute of Social and Preventive Medicine, University of Bern, Switzerland, ${ }^{10}$ Hospital for Infectious Diseases "Dr. Victor Babes", Bucharest, Romania, ${ }^{11}$ Emma Children's Hospital, Academic Medical Center, Amsterdam, The Netherlands, ${ }^{12}$ University Children's Hospital, Munich, Germany, ${ }^{13}$ Hôpital La Citadelle, Liège, Belgium, ${ }^{14}$ Erasmus MC Sophia Children's Hospital, Rotterdam, The Netherlands and ${ }^{15}$ Department of Pediatrics, Università di Padova, Padova, Italy

* Corresponding author
\end{abstract}

from Fourth Dominique Dormont International Conference. Host-Pathogen Interactions in Chronic Infections Paris, France. 13-15 December 2007

Published: 9 April 2008

Retrovirology 2008, 5(Suppl I):O25 doi:10.1 I86/I742-4690-5-SI-O25

This abstract is available from: http://www.retrovirology.com/content/5/SI/O25

(c) 2008 Goetghebuer et al.; licensee BioMed Central Ltd.

\section{Background}

Without antiretroviral therapy (ART), approximately $20 \%$ of HIV-1 vertically infected infants develop severe disease manifestations before the age of 1 year [1] and surrogate markers poorly predict infants at higher risk of rapid disease progression. Several small prospective and retrospective studies in developed countries have suggested that ART initiated early in life could prevent this rapid clinical and immunologic deterioration [2-6].

Because of the small number of HIV-infected infants delivered in industrialized countries where mother to child transmission prophylaxis is widely applied, a prospective study of early versus delayed ART is currently not feasible. Implementation of early ART has varied across countries and over time since 1996 in Europe. The objective of this collaborative study was to compare the out- come of infants who received ART early in life with the outcome of those with deferred treatment.

\section{Materials and methods}

Children born between 01/09/96 and 31/12/2004 to mothers with known HIV infection at birth, who received neonatal prophylaxis, and diagnosed with HIV before age 3 months were eligible. The children who were identified as HIV-infected at the same time or after being diagnosed with AIDS, and children who develop AIDS before the age of 3 months were excluded. Thirteen prospective and retrospective cohorts from 11 European countries participated, enrolling a total of 210 eligible infants. Data including general demographics and pregnancy data, details of prophylaxis and ART in early life, CDC events and death, immunological and virological measurements since birth, were collected and pooled. The risk of AIDS/ death was estimated by Kaplan-Meier survival analysis, 
and compared between the groups of infant treated or not treated before 3 months of age. Cox regression was used to estimate hazard ratios.

\section{Results}

Among the 210 children, 21 developed AIDS and 3 died. The exposure to treatment was heterogeneous among cohorts. Overall ART and Highly active ART were initiated in $59 \%$ and $48 \%$ of the infants before 3 months of age and in $87 \%$ and $76 \%$ by one year, respectively.

Treatment was initiated before the age of 3 months in 124 infants. There was no significant difference in demographic, pregnancy and delivery characteristics between the two groups. Moreover the proportion of infants with early treatment did not vary significantly over time. As shown in figure 1, we found that the risk of developing AIDS/death at one year was $1.6 \%$ in infants treated before the age of 3 months compared to $11.7 \%$ in infants who started treatment later $(\mathrm{p}<0.001)$. At 5 years the risks were $4.6 \%$ and $21.5 \%$ respectively. Deferred treatment was associated with a five-fold higher risk of AIDS has compared with treatment before 3 months of age (crude hazard ratio $=5.0 ; 95 \%$ CI: 2.0-12.6). Adjustment for ethnicity, birth weight, breast feeding, number and class of neonatal prophylaxis, number and class of drug in first treatment did not substantially affect the hazard ratio.

\section{Conclusion}

The preliminary results of this retrospective collaborative study suggest a significant association between ART

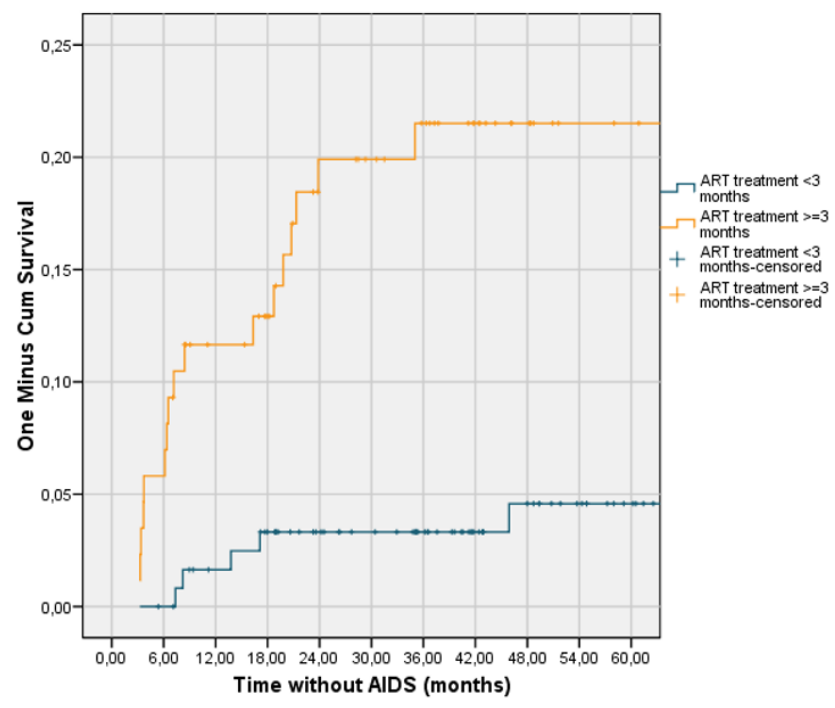

Figure I

Time from birth to AIDS/death comparing children treated before 3 months of age and children not treated before 3 months of age. started before the age of 3 months and a lower subsequent incidence of AIDS/death in infancy.

\section{Acknowledgements}

The study was supported by Paediatric European Network for the Treatment of AIDS. We thank all collaborators of the European Infant Collaborative study.

\section{References}

I. Blanche S, Newell ML, Mayaux MJ, et al.: Morbidity and mortality in European children vertically infected by HIV-I. The French Pediatric HIV Infection Study Group and European Collaborative Study. J Acquir Immune Defic Syndr Hum Retrovirol 1997, 14(5):442-450.

2. Luzuriaga K, McManus M, Mofenson L, Britto P, Graham B, Sullivan JL: A trial of three antiretroviral regimens in HIV-I-infected children. N Engl J Med 2004, 350(24):247 I-2480.

3. Faye A, Le Chenadec J, Dollfus C, et al.: Early versus deferred antiretroviral multidrug therapy in infants infected with HIV type I. Clin Infect Dis 2004, 39(II): 1692-1698.

4. Aboulker JP, Babiker A, Chaix ML, et al.: Highly active antiretroviral therapy started in infants under 3 months of age: 72-week follow-up for CD4 cell count, viral load and drug resistance outcome. Aids 2004, I 8(2):237-245.

5. Van der Linden D, Hainaut M, Goetghebuer T, et al:: Effectiveness of early initiation of protease inhibitor-sparing antiretroviral regimen in human immunodeficiency virus-I vertically infected infants. Pediatr Infect Dis J 2007, 26(4):359-36I.

6. Chiappini E, Galli L, Tovo PA, et al.: Virologic, immunologic, and clinical benefits from early combined antiretroviral therapy in infants with perinatal HIV-I infection. Aids 2006, 20(2):207-2I5.
Publish with Biomed Central and every scientist can read your work free of charge

"BioMed Central will be the most significant development for disseminating the results of biomedical research in our lifetime." Sir Paul Nurse, Cancer Research UK

Your research papers will be:

- available free of charge to the entire biomedical community

- peer reviewed and published immediately upon acceptance

- cited in PubMed and archived on PubMed Central

- yours - you keep the copyright 